\title{
Hydroxychloroquine for the treatment of COVID-19: an approach based on the philosophy of science and heuristics
}

\section{Davi Jorge Fontoura Solla $\mathbb{C}$}

It is unprecedent such a case of a medication with so few and flawed studies that has so quickly influenced the clinical practice of so many physicians around the world. Unfortunately, this is not the first time we witness a treatment to be picked up and go mainstream despite lack of good evidence, but none has done so in such a brief period of time. Here we will discuss some basic principles on the philosophy of science that should guide our critical appraisal of the available evidence and how heuristics may be biasing medical practices and shaping public opinion.

\section{The null hypothesis principle and the inductive problem}

As a basic assumption, we should be aware of the probability of the null hypothesis to be higher than the alternative hypothesis. In other words, most published research findings are false ${ }^{1}$. Most results from pre-clinical and phase I/ II studies are not confirmed in phase III studies. One of the main reasons for that is related to the primordial conception of the hypothesis. It is not uncommon (not to say, routine) to medical treatment hypotheses to be originated from inductive models (as opposed to the hypotheticaldeductive reasoning) $)^{2}$. That is, many hypotheses are formulated a posteriori (alongside an attractive physiopathological explanation) after empirical observations, ex post facto, although not always self-admitted $1,3-5$. This practice is known as HARKingHypothesizing After the Results are Known ${ }^{6}$ - and contrasts with an a priori hypothesis followed by a study specifically designed to refute it or not.

The first reported uses of chloroquine for the treatment of an infectious disease (infectious mononucleosis) dates from 60 years ago, before its viral etiology was discovered ${ }^{\mathrm{z}}$. Since then, numerous studies have followed for several viruses (influenza, Epstein-Barr, Ebola, Zika, Chikungunya) with heterogeneous results, including deleterious ones (whether viral replication increase or clinical worsening $)^{8}$. Biological systems are much more complex and dynamic than the inert environment of in vitro studies. It is not always possible or safe to achieve the preclinical therapeutic dose of the study drug and its pharmacodynamics when interacting with other drugs, hormones and 
cytokines is almost unpredictable to say the least. Moreover, this unpredictability is directly correlated with the severity of the disease and the extent of organ dysfunctions. The studies responsible for raising the hype around the possible effectiveness of Hydroxychloroquine (HCQ) against Coronavirus Disease 19 (Covid-19) were performed in vitro, in animals and in small clinical studies ${ }^{9,10}$. Clinical trials with appropriate methodology and sample size are still in progress ${ }^{11-14}$.

\section{The fragile biological plausibility}

Another fundamental wariness concerns the biological plausibility of the large effect size advertised by some HCQ enthusiasts. Claims of up to zero deaths and zero hospitalizations have been made on the early anecdotal descriptions of the HCQ effect $\frac{15}{5}$. Since there is no treatment one-hundred percent effective in medicine, discredit on the supposedly found benefits is justified. Even disregarding these enthusiastic hyperboles, the probability of a game-changing effect remains low. Although drug repurposing is a wellestablished research strategy, the success rate is poor ${ }^{16}$. Specificity is one of Hill's causality criteria, which also give some analogical guidance on the evaluation of potential therapies. Unless based on the collateral effects, non-specific therapies indicated for different diseases due to distinct pathophysiological processes hardly present large effect sizes for the repurposed target. By contrast, highly specific therapies tend to be highly beneficial when proven effective (e.g. antibody, molecular markers and gene based therapies $)^{17}$. There is a recurring argument emphasizing the HCQ perceived safety and low $\cos ^{18-20}$. Nevertheless, when a treatment is unequivocally effective, we do use it despite adverse effects and despite the associated cost.

\section{What drives the general medical community and society behavior towards the use of HCQ for the treatment of Covid-19?}

Some well-designed clinical trials have been struggling to recruit patients worried of having a chance not to receive HCQ (DISCOVERY trial21) while other clinical trials coordinators have abdicated beforehand from including a placebo controlled arm due to the fear of not being able to include patients (COALITION II trial11, personal communication). Given the scarce data supporting HCQ for the treatment of Covid-19, how did we end up in such a framework?

Judgement and decision making commonly occur under unconscious mental processes called heuristics, which makes us prone to a variety of biases. Some of these heuristics and/or biases may play a role on the current global scenario. To begin with, physicians tend to overestimate the benefit of their actions and underestimate the negative risks of the same actions, what is known as self-serving bias $^{22}$. At the same time, the disseminated impression of absence of a treatment for Covid-19 (which is somewhat questionable, since we do know a lot on how to manage severe viral infections) conflicts with the generalized physician mindset that urges: "we must do something" - the active physician mindset. The ground for the adoption of unproven therapies is now settled.

Hyperbolic and fanciful rumors lead to higher broadcasting than wary and realistic reports. Thus, premature claims of scientific discoveries leading to possible new treatments overflow the media and are intensified by social media bubbles. This predisposes to the availability heuristic, a cognitive bias through which the frequency or probability of an event being true is judged by the number of instances of it that can readily be recalled 23 . "If everybody is talking about the benefit of HCQ for Covid-19, then it must be true". Once accepted this belief, evidences that might confirm it are overvalued, while evidences that might disconfirm or refute it are ignored - the confirmation bias $^{24}$. The likelihood of new, opposite facts or logical reasoning changing one's belief is disappointing due to the uncomfortable state of mental conflict caused by the disagreement between the belief and the new evidence. This cognitive dissonance bias is especially painful in the setting of a commitment bias related to past ideas and public behavior ${ }^{25}$.

\section{False dilemma as the basis for a new, potential case of medical reversal}

Many people, including politicians and health care workers, have argued that given the pandemic 
emergency there is no time available to pursue perfect clinical trials and, thus, the adoption of HCQ is justified. This is a false dilemma/dichotomy. Although it is true that large, multicenter, randomized, controlled clinical trials (RCT) well-powered for all severity strata and subgroups within the Covid-19 spectrum may not be feasible in a short period of time, this does not translate into the acceptance of the results of extremely flawed studies. Small, proof-of-concept RCT or well-designed observational, non-interventional studies (either cohorts or case-controls) can also provide good guidance ${ }^{26}$. Unfortunately, the scientific community demand for minimum standards before the wide adoption of HCQ or other therapies has even been pejoratively classified as scientism.

The current scenario is propitious to a new case of medical reversal: the phenomenon of a new trial superior to predecessor because of better design, increased power, or more appropriate controls contradicting current clinical practice ${ }^{27}$. Reversing widespread medical practices involves time, resistance and costs (financial and, sometimes, lives), in addition to societal loss of credibility in the medical community ${ }^{28}$.

\section{The individualist ethical fallacy on the indiscriminate compassionate use of HCQ for Covid-19}

The argument of using HCQ as a hope can be understood as an individualist ethical fallacy, which is the misconception of confusing two distinct and very different notions: the view that the dictates of the individual conscience are always right; and the view that no individual should act against the dictates of conscience ${ }^{29}$. Action and belief must be treated separately. Compassionate use would be justified when the manifestation of the desire to use HCQ comes from the patient or its family, especially for severe Covid-19 cases. In such a situation, coupled with a weighted regard to the patient's autonomy, the benefit of the doubt is in favor of the unproven therapy, given the potential risks were properly disclosed. However, it is a completely different situation to, based on the doctor's belief, indiscriminately use of a medication that lacks minimum scientific evidence background. To obscure the circumstance even further, we should not overlook that informed consent and shared decision is commonly an utopia, given the high disproportion on hierarchical position and technical knowledge between the patient and his doctor. To indiscriminately use HCQ for Covid-19 is a trivialization and disrespect to the hope of patients and family members. A realistic therapeutic plan tied to empathetic prognosis disclosure would be more valuable than a fallacious hope.

In conclusion, there is a need to rescue the principle of non-maleficence - not only applied for the individual patient, but also for the community. There is no hope outside science and ethics.

\section{Competing interests}

No financial, legal or political competing interests with third parties (government, commercial, private foundation, etc.) were disclosed for any aspect of the submitted work (including but not limited to grants, data monitoring board, study design, manuscript preparation, statistical analysis etc.).

\section{References}

1. Ioannidis JPA. Why Most Published Research Findings Are False. PLoS Med. 2005;2(8):e124. doi: 10.1371/journal.pmed.0020124

2. Popper KR. Logik der Forschung. Berlin: Akademie Verlag; 1934.

3. Peto R. Current misconception 3: That subgroup-specific trial mortality results often provide a good basis for individualising patient care. Br J Cancer. 2011;104(7):1057-8. doi: 10.1038/ bjc.2011.79

4. Rubin M. When does HARKing hurt? Identifying when different types of undisclosed post hoc hypothesizing harm scientific progress. Rev Gen Psychol. 2017;21(4):308-20. doi: 10.1037/ gpr0000128

5. Lewandowsky S, Oberauer K. Low replicability can support robust and efficient science. Nat Commun. 2020;11(358):1-12. doi: 10.1038/s41467-019-14203-0

6. Kerr NL. HARKing: Hypothesizing after the results are known. Personal Soc Psychol Rev. 1998;2(3):196-217. doi: $10.1207 /$ s15327957pspr0203 4

7. Gothberg LA. Severe infectious mononucleosis treated with chloroquine phosphate. J Am Med Assoc. 1960;173:53-7. doi: 10.1001/jama.1960.73020190016012 
8. Ferner RE, Aronson JK. Chloroquine and hydroxychloroquine in covid-19. BMJ. 2020;369:m1432 doi: 10.1136/bmj.m1432

9. Gautret P, Lagier J-C, Parola P, Hoang VT, Meddeb L, Mailhe $M$ et al. Hydroxychloroquine and azithromycin as a treatment of COVID-19: results of an open-label non-randomized clinical trial. Int J Antimicrob Agents. 2020:105949. doi: 10.1016/j. ijantimicag.2020.105949

10. Shamshirian A, Hessami A, Heydari K, Alizadeh-Navaei R, Ebrahimzadeh MA, Ghasemian R et al. Hydroxychloroquine Versus COVID-19: A Rapid Systematic Review and Meta-Analysis. MedRxiv. 2020. doi: $10.1101 / 2020.04 .14 .20065276$

11. U.S. National Library of Medicine. Safety and Efficacy of Hydroxychloroquine Associated With Azithromycin in SARS-CoV2 Virus (Coalition Covid-19 Brasil II) 2020. [Internet]. 2020. [acesso em 2020 abr 23]. Disponível em: https://clinicaltrials.gov/ct2/ show/NCT04321278

12. U.S. National Library of Medicine. Safety and Efficacy of Hydroxychloroquine Associated With Azythromycin in SARS-Cov-2 Virus (Coalition Covid-19 Brasil I). [Internet]. 2020. [acesso em 2020 abr. 23]. Disponível em: https://clinicaltrials.gov/ct2/show/ NCT04322123

13. U.S. National Library of Medicine. Trial of Treatments for COVID-19 in Hospitalized Adults (DisCoVeRy). [Internet]. 2020. [acesso em 2020 abr. 23]. Disponível em: https://clinicaltrials.gov/ ct2/show/NCT04315948

14. World Health Organization. "Solidarity" clinical trial for COVID-19 treatments 2020. [Internet]. 2020. [acesso em 2020 abr. 23]. Disponível em: https://www.who.int/emergencies/diseases/ novel-coronavirus-2019/global-research-on-novel-coronavirus2019-ncov/solidarity-clinical-trial-for-covid-19-treatments

15. Roose K, Rosenberg M. Touting virus cure, "simple country doctor" becomes a right wing star. New York Times. 2020. [Internet]. 2020. [acesso em 2020 abr. 21]. Disponível em: https://www.nytimes.com/2020/04/02/technology/doctor-zelenkocoronavirus-drugs.html

16. Neuberger A, Oraiopoulos N, Drakeman D. Renovation as innovation: is repurposing the future of drug discovery research? Drug Discov Today 2019;24(1):1-3. doi: 10.1016/j. drudis.2018.06.012

17. Pushpakom S, lorio F, Eyers PA, Escott KJ, Hopper S, Wells A et al. Drug repurposing: progress, challenges and recommendations. Nat Publ Gr. 18(1):41-58. doi: 10.1038/nrd.2018.168
18. Liu J, Cao R, Xu M, Wang X, Zhang H, Hu H et al. Hydroxychloroquine, a less toxic derivative of chloroquine, is effective in inhibiting SARS-CoV-2 infection in vitro. Cell Discov. 2020;6:16. doi: $10.1038 / 541421-020-0156-0$

19. Duqueroy V. COVID-19: More Hydroxychloroquine Data From France. Medscape 2020:3. [Internet]. 2020. [acesso em 2020 abr. 29]. Disponível em : https://www.medscape.com/ viewarticle/927758\#vp_3

20. Monteiro WM, Brito-Sousa JD, Baía-da-Silva D, Melo GC, Siqueira AM, Val F et al. Driving forces for COVID-19 clinical trials using chloroquine: the need to choose the right research questions and outcomes. Rev Soc Bras Med Trop. 2020;53:e20200155. doi: 10.1590/0037-8682-0155-2020

21. Sciama Y. Is France's president fueling the hype over an unproven coronavirus treatment? [Internet]. 2020. Disponível em: https://pulitzercenter.org/reporting/frances-president-fuelinghype-over-unproven-coronavirus-treatment

22. Larson Junior JR. Evidence for a self-serving bias in the attribution of causality. J Pers. 1977;45(3):430-41. doi: $10.1111 /$ j.1467-6494.1977.tb00162.x

23. Tversky A, Kahneman D. Availability: A heuristic for judging frequency and probability. Cogn Psychol 1973;5(2):207-32. doi: $\underline{10.1016 / 0010-0285(73) 90033-9}$

24. Wason PC. On the failure to eliminate hypotheses in a conceptual task. Q J Exp Psychol. 1960;12:129-40. doi: 10.1080/17470216008416717

25. Festinger L. A Theory of Cognitive Dissonance. Redwood City, California: Stanford University Press; 1957.

26. Gershon AS, Jafarzadeh SR, Wilson KC, Walkey AJ. Clinical Knowledge from Observational Studies. Everything You Wanted to Know but Were Afraid to Ask. Am J Respir Crit Care Med. 2018;198:859-67. doi: 10.1164/rccm.201801-0118PP

27. Prasad V, Gall V, Cifu A. The Frequency of Medical Reversal. Arch Intern Med. 2011;171(18):1675. doi: $10.1001 /$ archinternmed.2011.295

28. Prasad VK, Cifu AS. Ending medical reversal : improving outcomes, saving lives. Baltimore, Maryland, USA: Johns Hopkins University Press; 2015.

29. Cohen B. Three Ethical Fallacies. Mind. 1977;86(341): 78-87. doi: $10.1093 / \mathrm{mind} / L X X X V I .341 .78$ 